\title{
Case From the Eyes of an Anatomist: Fistula Between Proximal of Left Anterior Descending Artery to Pulmonary Artery
}

\author{
Musa Muhtaroglu ${ }^{\mathrm{a}, \mathrm{b}}$, Sevda Lafci Fahrioglu ${ }^{\mathrm{a}}$, Sezgin Ilgi ${ }^{\mathrm{a}}$
}

\begin{abstract}
Advanced diagnostic systems and screening services for health care have made it possible to improve the detection of congenital cardiovascular abnormalities, including coronary artery variations. Many coronary artery fistulas are congenital, and this can also be reported in patients with normal heart anatomy. In this report, we present a patient with a fistula between left anterior descending artery and pulmonary artery which was diagnosed incidentally with conventional angiography.
\end{abstract}

Keywords: Coronary artery fistula; Fistula between LAD and pulmonary artery; Congenital coronary artery anomalies

\section{Introduction}

Anomalies in the coronary artery include origin, termination, structure, or path anomalies. Coronary artery fistulas (CAFs) are known as terminating defects and are considered severe congenital anomalies. A CAF involves a sizable comminucation between a coronary artery, bypassing the myocardial capillary bed and entering either a chamber of the heart or any segment of the systemic or pulmonary circulation [1]. These lesions are similar in their pathophysiology, and often referred to as coronary arteriovenous fistulas (CAVFs). The relation of the coronary artery to the pulmonary artery may also be included under this category. However, if the so-called artery occurs only from the pulmonary trunk without a clear connection to the aorta, it is known as the pulmonary artery's unusual origin [2]. In most cases, small fistulas never compromise the circulation of the hemodynamic imbalances. The larger fistu-

Manuscript submitted February 7, 2021, accepted February 22, 2021

Published online March 5, 2021

aAnatomy Department, Faculty of Medicine, Near East University, Nicosia, Cyprus

${ }^{b}$ Corresponding Author: Musa Muhtaroglu, Anatomy Department, Faculty of Medicine, Near East University, Nicosia, Cyprus.

Email: musamuhtaroglu@hotmail.com

doi: https://doi.org/10.14740/jmc3676 las can cause the phenomenon of coronary artery steal, ultimately causing ischemic myocardial segment perfusion at the segment of the coronary artery that is being fed by the fistulization-related structures. The pathophysiological feature of the coronary fistula is myocardial leak or decrease in myocardial blood flow distal to the direction of the coronary fistula. The mechanism is connected to the gradient of diastolic pressure and to a low-pressure receiving cavity runoff from the coronary vasculature. When the fistula is large, the intracoronary diastolic infusion pressure decreases gradually [3]. Based on results in traditional coronary angiography trials, the prevalence of CAFs was considered to be $0.05-0.25 \%$ in the population [4]. The majority of CAFs are diagnosed incidentally during cardiac catheterization. However, some studies have shown that coronary computed tomography (CT) angiography detects coronary artery anomalies at a higher rate than traditional coronary angiography $[5,6]$.

\section{Case Report}

A 53-year-old female was admitted to the hospital due to chest pain. She had a history of hypertension and atrial fibrillation. She had no drug history. Her cardiovascular physical examination was normal. All blood investigations were normal including renal parameters. The patient's resting electrocardiogram (ECG) was normal. She underwent an elective coronary $(\mathrm{CAG})$ due to indications of stable.

Coronary angiography revealed no stenosis in the coronary arteries but there was a fistulation between the proximal left anterior descending (LAD) artery and the pulmonary artery (Fig. 1). After the coronary angiography, her chest pain disappeared. No catheterization or surgical intervention was done. Due to her atrial fibrillation, she was discharged with anticoagulants and beta-blockers. The patient has remained asymptomatic with no clinical or hemodynamic effects during the clinical follow-up.

\section{Discussion}

The fistula of the coronary artery is characterized as unusual contact between the coronary arteries and a systemic or pulmonary circulation component. In several studies, the inci- 


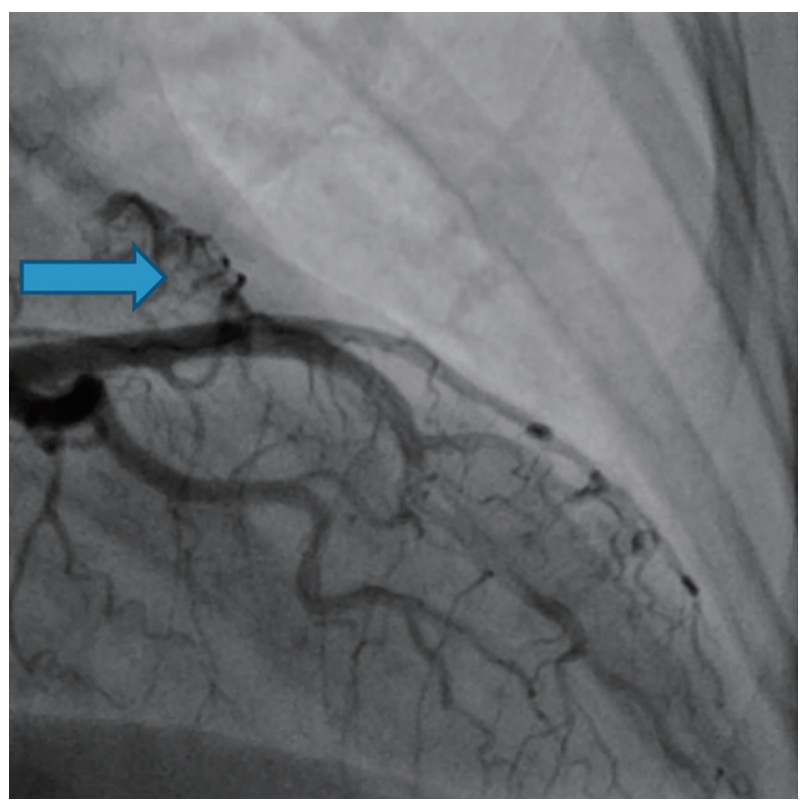

Figure 1. The fistula of the coronary artery (arrow). Angiography reveals the pulmonary fistula to proximal LAD. LAD: left anterior descending.

dence of CAF has been reported as less than $1 \%$. The word "coronary-cameral fistula" refers to the contact between a cardiac chamber and the coronary arteries. Although most are congenital, in cases of trauma, as a complication of coronary artery bypass surgery and in some cases of Takayasu's arteritis, acquired fistulas have been reported [5]. Most patients are asymptomatic and may develop signs of angina and dyspnea if other disorders are diagnosed, such as coronary artery disease or heart failure. For coronary fistulas, there is no specific treatment procedure, but both surgical intervention and trans-catheter embolization have been reported. Surgical treatment rather than embolization can be a realistic choice for patients who are symptomatic secondary to the CAF but remains controversial in patients who are asymptomatic [7]. Research published in 2017 reported that none of the 21 adult patients who had surgery with CAF ligation had surgical or any hospital mortality [8]. Surgical ligation or transcatheter closure (TCC) therapeutic intervention is typically performed in patients with symptomatic fistula, or in the event of a complication. The preferred approach is percutaneous TCC, since it is less invasive and prevents the potential risks of surgery. Anatomy, however, may not be conducive to TCC, especially when the vessel is tortuous or has a large fistula; surgical closure is preferred in these cases. In terms of treatment for asymptomatic patients, there is no general consensus. Closer follow-up can be considered in patients that have small fistulas with significant shunting [9].

\section{Conclusions}

The general consensus in symptomatic patients recommends surgical treatment if the fistula has a compromised cardiac function or if the etiology underlies any other related sequelae. However, there was a discussion about the size and location of fistulas in relation to surgical treatment in an asymptomatic patient [10]. In the current case, an asymptomatic coronary fistula has originally been described with no clinical or hemodynamic effect, therefore a clinical follow-up with the patient remaining asymptomatic was chosen. This report demonstrates once again that individualized consideration is important when the asymptomatic CAF is diagnosed.

\section{Acknowledgments}

First and foremost, we are very grateful to Dr. Burhan Nalbantoglu State Hospital Cardiology Specialist Dr. Osman Beton and Dr. Gulgun Vaiz for their invaluable advice, continued support and patience during our case study.

\section{Financial Disclosure}

None to declare.

\section{Conflict of Interest}

We declare that we have neither a conflict of interest nor a suggestion of interest regarding the content of this paper.

\section{Informed Consent}

In this case, informed consent was not required.

\section{Author Contributions}

Musa Muhtaroglu presented the proposal, collected data, made an angiography $\mathrm{CD}$ and edited the manuscript. This paper was written by Muhtaroglu and Lafci Fahrioglu. Musa Muhtaroglu was the lead researcher for this report. Prof. Sezgin has provided their expertise and has supervised the editing of the manuscript. All authors reviewed and discussed the results before the paper was submitted.

\section{Data Availability}

The data supporting the results of this study are available in the reference itself.

\section{References}

1. Padfield GJ. A case of coronary cameral fistula. Eur J Echocardiogr. 2009;10(5):718-720.

2. Cemri M, Sahinarslan A, Akinci S, Arslan U. Dual coronary artery-pulmonary artery fistulas. Can J Cardiol. 2009;25(3):e95.

3. Schamroth C. Coronary artery fistula. J Am Coll Cardiol. 
2009;53(6):523.

4. Lim JJ, Jung JI, Lee BY, Lee HG. Prevalence and types of coronary artery fistulas detected with coronary CT angiography. AJR Am J Roentgenol. 2014;203(3):W237-243.

5. Sunkara A, Chebrolu LH, Chang SM, Barker C. Coronary Artery Fistula. Methodist Debakey Cardiovasc J. 2017;13(2):78-80.

6. Yun G, Nam TH, Chun EJ. Coronary Artery Fistulas: Pathophysiology, Imaging Findings, and Management. Radiographics. 2018;38(3):688-703.

7. Said SA. Current characteristics of congenital coronary artery fistulas in adults: A decade of global experience.
World J Cardiol. 2011;3(8):267-277.

8. Albeyoglu S, Aldag M, Ciloglu U, Sargin M, Oz TK, Kutlu H, Dagsali S. Coronary Arteriovenous Fistulas in Adult Patients: Surgical Management and Outcomes. Braz J Cardiovasc Surg. 2017;32(1):15-21.

9. Armsby LR, Keane JF, Sherwood MC, Forbess JM, Perry SB, Lock JE. Management of coronary artery fistulae. Patient selection and results of transcatheter closure. J Am Coll Cardiol. 2002;39(6):1026-1032.

10. Gelman S, et al. A fistula where? Left anterior descending to pulmonary artery fistula. Journal of Medical Cases. 2020; 11(10):306-308. 